\title{
INVESTIGATION OF ELECTRICAL CONDUCTION IN VANADATE BASED GLASSES
}

\author{
R. V. BARDE \\ Dept. of Engg. Physics, H.V.P.M. College of Engg. \& Technology, Amravati 444 605, India. \\ rajeshbarde1976@gmail.com

\section{S. A. WAGHULEY} \\ Department of Physics, Sant Gadge Baba Amravati University, Amravati 444 602, India. \\ sandeepwaghuley@sgbau.ac.in
}

\begin{abstract}
The binary glassy systems $60 \mathrm{~V}_{2} \mathrm{O}_{5}-\left(40-\mathrm{x}_{2} \mathrm{P}_{2} \mathrm{O}_{5}-\mathrm{xB}_{2} \mathrm{O}_{3}\right.$ were prepared by melt quenching technique. The mole of $\mathrm{B}_{2} \mathrm{O}_{3}$ was varies from 5 to 20 mol \% with constant mol \% of $\mathrm{V}_{2} \mathrm{O}_{5}$ during preparation of glass samples. The dc electrical conductivity of samples was measured in temperature range 303-473 $\mathrm{K}$ and found to be higher for sample $60 \mathrm{~V}_{2} \mathrm{O}_{5}-20 \mathrm{P}_{2} \mathrm{O}_{5}-20 \mathrm{~B}_{2} \mathrm{O}_{3}$. Using the Arrhenius equation of conductivity, the activation energy of conduction is estimated. The conduction in these glasses is takes place by phonon-assisted hopping between the localized states.
\end{abstract}

Keywords: Glass; Ceramics; Electrical conduction

\section{Introduction}

Fast ion-conducting glasses have been paid considerable attention for the recent past for their potential applications in solid state electrochemical devices, such as batteries, sensors, etc. There are many experimental and theoretical reports on ion conduction of these fast ion-conducting glasses. However, the conduction mechanism of these glasses is not properly understood yet because of the difficulty in separating the contribution of the ion concentration and mobility from the measured conductivity ${ }^{\mathbf{1 - 3}}$. Glasses containing large amounts of transition metal oxides exhibit electronic conductivity. Their electrical properties are determined by the presence of the transition metal ions in two different valence states and the conductivity is described by the mechanism of small polaron hopping between such ions ${ }^{4}$.

The structure of $\mathrm{V}_{2} \mathrm{O}_{5}$ is built of octahedrons, where the pentavalent vanadium has 5coordination with oxygen atoms, the $\mathrm{V}_{2} \mathrm{O}_{5}$-rich glasses in which $\mathrm{V}_{2} \mathrm{O}_{5}$ acts as the network former have the network structure mainly consisting of corner-sharing branched $\mathrm{VO}_{4}$ tetrahedral of the same structural units as found in phosphate glasses. The network structure was reported to be made-up unaffected $\mathrm{VO}_{5}$ groups as in vitreous $\mathrm{V}_{2} \mathrm{O}_{5}$ and affected $\mathrm{VO}_{5}$ groups with alkaline earth ions in contrast to the vanadate glasses formed by conventional network formers in which only unaffected $\mathrm{VO}_{5}$ groups are present. These glasses are known to contain $\mathrm{V}^{4+}$ and $\mathrm{V}^{5+}$ ions where the electrical conduction was 
attributed to the hopping of $3 \mathrm{~d} 1$ unpaired electron from $\mathrm{V}^{4+}$ to $\mathrm{V}^{5}+$ site, which induces a polarization of the vanadium ion around it and forms a polarons. Vanadate has received greater attention as a new branch in semi-conducting glasses because of its wider glassforming region in the phase diagram and its possible technological applications in threshold switching, memory switching, electrical threshold, electrochemical batteries and optical switching devices ${ }^{5-6}$.

$\mathrm{B}_{2} \mathrm{O}_{3}$ glasses are found to be very interesting amorphous materials whenever the specific structure and physical properties of which taken into consideration. In these glasses, two groups of bands are obtained: (i) due to trigonal $\mathrm{BO}_{3}$ and (ii) due to the tetrahedral $\mathrm{BO}_{4}$ units. By the addition of transition metal ions to the borate glasses, they would exhibit specific physical properties ${ }^{7-9}$.

In the present work, glass samples of $60 \mathrm{~V}_{2} \mathrm{O}_{5}-(40-\mathrm{x}) \mathrm{P}_{2} \mathrm{O}_{5}-\mathrm{x} \mathrm{B}_{2} \mathrm{O}_{3}$ are prepared by melt-quenching method. The dc conductivity is investigated for synthesized glass system. The optical properties studied form FTIR analysis. The glass sample was characterized by XRD.

\section{Experimental}

The glass sample of $60 \mathrm{~V}_{2} \mathrm{O}_{5^{-}}(40-\mathrm{x}) \mathrm{P}_{2} \mathrm{O}_{5}-\mathrm{x}_{2} \mathrm{O}_{3}$ with $\mathrm{x}=5,10$ and $20 \mathrm{~mol} \%$ were prepared by the melt quenching technique. Required quantities of $\mathrm{V}_{2} \mathrm{O}_{5}, \mathrm{P}_{2} \mathrm{O}_{5}$ and $\mathrm{H}_{3} \mathrm{BO}_{3}$ were mixed together by grinding the mixture repeatedly to obtain a fine powder. The mixture was dried at $373 \mathrm{~K}$ for $30 \mathrm{~min}$. Then the mixture was melted in a silica crucible in an electrically heated furnace under ordinary atmospheric conditions at a temperature of about $1100 \mathrm{~K}$ for $3 \mathrm{~h}$ to homogenize the melt and the melts was stirred to remove $\mathrm{CO}_{2}$. The melted mixture was poured on mercury leveled $2 \times 1 \mathrm{~cm}^{2}$ silica substrate to form bulk glass. For electrical contact, the silver electrodes were deposited on adjacent sides. The samples were kept at $400 \mathrm{~K}$ for drying the silver contacts. The $\mathrm{X}$-ray diffraction pattern was recorded on Rigaku X-ray diffractometer using $\mathrm{Cu} K \alpha$ radiation $(\lambda=1.54 \AA$ ) $)$. The diffractogram was in terms of $2 \theta$ in the range $10^{\circ}-70^{\circ}$. The FTIR transmission spectra of the glasses in the $400-4000 \mathrm{~cm}^{-1}$ spectral range were obtained with a Shimazu FT-IR spectrometer, using the $\mathrm{KBr}$ pellet technique. The temperature dependence of the electrical conductivity was measured by using two probe methods.

\section{Results and Discussion}

\subsection{X-Ray diffraction (XRD) analysis}

Fig. 1 shows the X-ray patterns of $60 \mathrm{~V}_{2} \mathrm{O}_{5^{-}}(40-\mathrm{x}) \mathrm{P}_{2} \mathrm{O}_{5}-\mathrm{x} \mathrm{B}_{2} \mathrm{O}_{3}$ with $\mathrm{x}=5,10$ and $20 \mathrm{~mol}$ $\%$ glass ceramic. The XRD spectra of sample was recorded between $2 \theta=10-90^{\circ}$. The Xray pattern of sample shows noisy spectra and the peak was observed at the position $25^{\circ}$ which is attributed to the amorphous halos nature of glass ceramics. 


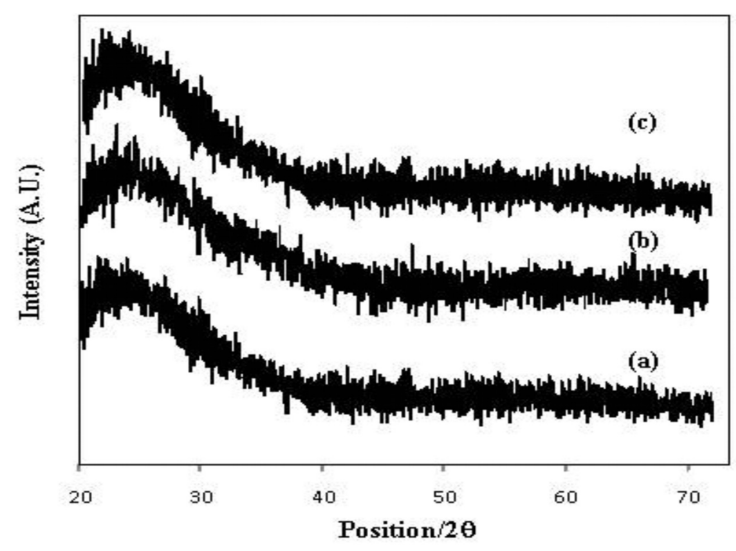

Fig. 1. XRD of $60 \mathrm{~V}_{2} \mathrm{O}_{5^{-}}(40-\mathrm{x}) \mathrm{P}_{2} \mathrm{O}_{5}-\mathrm{x} \mathrm{B}_{2} \mathrm{O}_{3}(\mathrm{a}) \mathrm{x}=5$, (b) $\mathrm{x}=10$ and (c) $\mathrm{x}=20$

\subsection{FTIR analysis}

FTIR have been carried out on powdered samples dispersed in $\mathrm{KBr}$ pellets and shown in Fig. 2 for the range $400-4000 \mathrm{~cm}^{-1}$. For all glasses, water band around $3400 \mathrm{~cm}^{-1}$ and $-\mathrm{OH}$ stretching peaks around $2400 \mathrm{~cm}^{-1}$ were observed. A peak was observed at 1646 $\mathrm{cm}^{-1}$ for all glasses and is independent of the concentration of the constituents of the glasses. The origin of these peaks is not obvious, but the $-\mathrm{OH}$ bending mode gives rise to absorption in this region and the possibility of some adsorbed water giving rise to these peaks cannot be ruled out. Hence, the bands observed in the range $1600-3400 \mathrm{~cm}^{-1}$ are possibly due to the hygroscopic nature of powdered samples. The first group of bands that occurs from 1200 to $1600 \mathrm{~cm}^{-1}$ is due to the asymmetric stretching-relaxation of the $\mathrm{B}-\mathrm{O}$ bond of triangle $\mathrm{BO}_{3}$ units. The second group lies between 900 and $1200 \mathrm{~cm}^{-1}$ and is

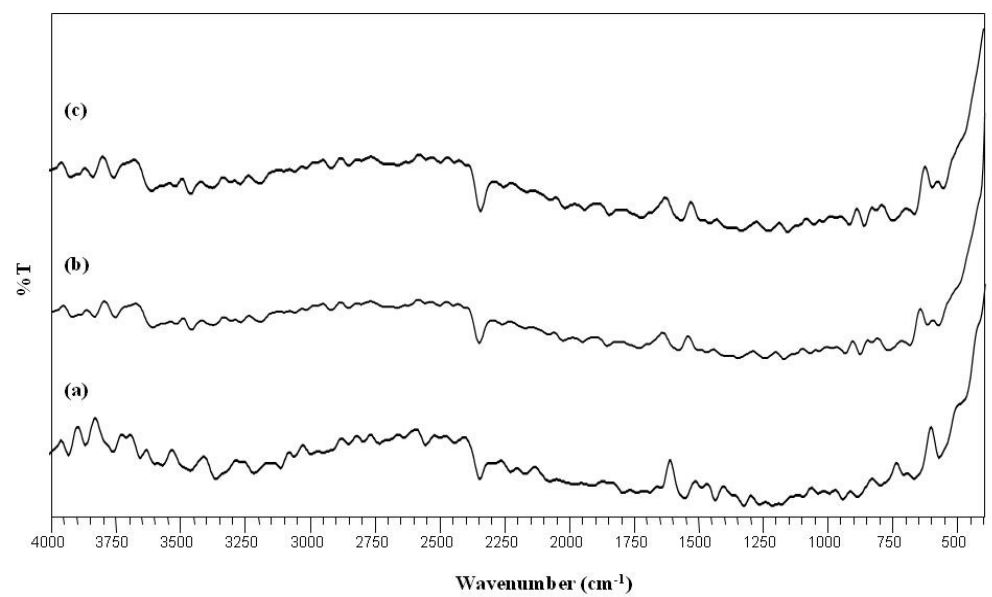

Fig. 2. FTIR specra of $60 \mathrm{~V}_{2} \mathrm{O}_{5^{-}}(40-\mathrm{x}) \mathrm{P}_{2} \mathrm{O}_{5}-\mathrm{x}_{2} \mathrm{~B}_{3}$ (a) $\mathrm{x}=5$, (b) $\mathrm{x}=10$ and (c) $\mathrm{x}=20$ 
due to $\mathrm{B}-\mathrm{O}$ bond stretching of the tetrahedral $\mathrm{BO}_{4}$ units. The third group is around 800 and $900 \mathrm{~cm}^{-1}$ and is due to the bending of $\mathrm{B}-\mathrm{O}-\mathrm{B}$ linkages in borate networks. The strong band observed for $\mathrm{V}_{2} \mathrm{O}_{5}$ at $1019 \mathrm{~cm}^{-1}$, which was reported at $1020 \mathrm{~cm}^{-1}$ by previous studies, has been assigned to the vibration of the isolated $\mathrm{V}=\mathrm{O}$ non-bridge bonds in the $\mathrm{VO}_{5}$ trigonal bipyramids ${ }^{\mathbf{1 0}}$. The absorption peaks at $1192,1445,1537$, and $1549 \mathrm{~cm}^{-1}$ are related with the fundamental asymmetrical stretching vibration of the $\mathrm{B}-\mathrm{O}$ bond of the trigonal $\mathrm{BO}_{3}$ units ${ }^{11,12}$.

\subsection{Temperature dependence of dc conductivity}

In general for a semiconducting materials, dc conductivity increases exponentially with temperature indicating that the conductivity is a thermally activated process. Mathematically, it can be expressed by the well-known Arrhenius relation as

$$
\sigma_{\mathrm{dc}}=\sigma_{0} \exp \left(-\mathrm{E}_{\mathrm{dc}} / \mathrm{KT}\right)
$$

where $\sigma_{0}$ is called pre-exponential factor, $E_{d c}$ is called the activation energy, $T$ is the absolute temperature and $\mathrm{k}$ is Boltzmann constant. These parameters are of significance to differentiate the nature of various conduction mechanisms. Fig. 3 shows temperature dependence of dc Conductivity $\left(\sigma_{\mathrm{dc}}\right.$, for $60 \mathrm{~V}_{2} \mathrm{O}_{5}-(40-\mathrm{x}) \mathrm{P}_{2} \mathrm{O}_{5}-\mathrm{x} \mathrm{B}_{2} \mathrm{O}_{3}$ with $\mathrm{x}=5,10$ and $20 \mathrm{~mol} \%$ respectively. From the figure, it is clear that the dc conductivity $\left(\sigma_{\mathrm{dc}}\right)$ varies exponentially with temperature, as $\ln \sigma_{\mathrm{dc}}$ vs. 1000/T curves are straight lines. Such behavior is consistent with equation (1). It is observed that the dc conductivity for all the glass compositions increases with the increase in temperature, indicating typical semi conducting behavior. The values of electrical parameters $\sigma_{\mathrm{dc}}, \mathrm{E}_{\mathrm{dc}}$ and $\sigma_{0}$ are listed in Table 1. From this we can say that the conduction occurs by phonon-assisted hopping between the localized states. The electrical conduction of the samples follows a mechanism in which the electron or hole hops from one localized site to the next.

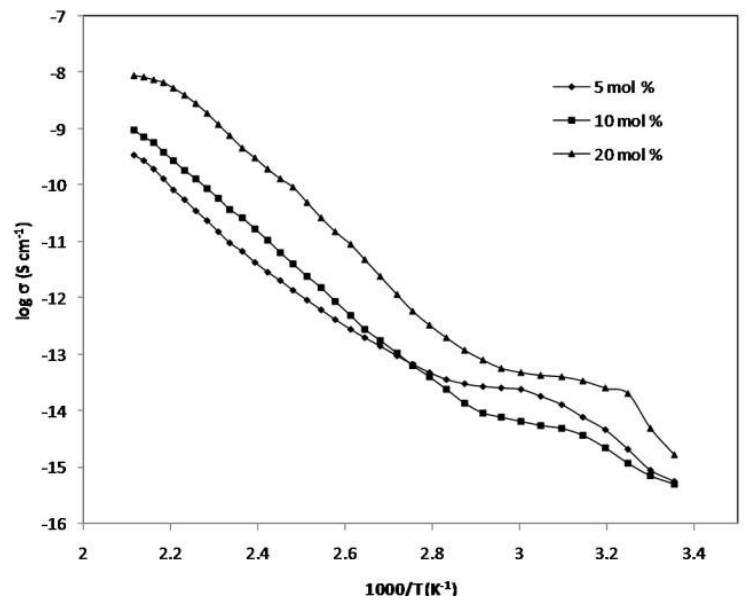

Fig. 3. Temperature dependent conductivity of $60 \mathrm{~V}_{2} \mathrm{O}_{5}-(40-\mathrm{x}) \mathrm{P}_{2} \mathrm{O}_{5}-\mathrm{x} \mathrm{B}_{2} \mathrm{O}_{3}$ 
Table 1. dc conductivity $(\sigma)$, activation energy $\left(\mathrm{E}_{\mathrm{dc}}\right)$, pre-exponential factor $\left(\sigma_{0}\right)$

\begin{tabular}{ccccc}
\hline Sample & $\begin{array}{c}\sigma_{\mathrm{dc}}\left(\mathrm{S} . C m^{-1}\right) \\
\text { at R.T. }\end{array}$ & $\begin{array}{c}\sigma_{\mathrm{dc}}\left(\mathrm{S} . \mathrm{Cm}^{-1}\right) \\
\text { at } 473 \mathrm{~K}\end{array}$ & $\mathrm{E}_{\mathrm{dc}}(\mathrm{eV})$ & $\sigma_{0}$ \\
\hline $\begin{array}{c}60 \mathrm{~V}_{2} \mathrm{O}_{5}-35 \mathrm{P}_{2} \mathrm{O}_{5} \\
-5 \mathrm{~B}_{2} \mathrm{O}_{3}\end{array}$ & $2.2469 \times 10^{-7}$ & $7.83388 \times 10^{-5}$ & 0.491 & 2.017784 \\
\hline $60 \mathrm{~V}_{2} \mathrm{O}_{5}-30 \mathrm{P}_{2} \mathrm{O}_{5}$ & $2.3877 \times 10^{-7}$ & $1.19982 \times 10^{-4}$ & 0.459 & 6.820958 \\
$-10 \mathrm{~B}_{2} \mathrm{O}_{3}$ & & & & \\
\hline $60 \mathrm{~V}_{2} \mathrm{O}_{5}-20 \mathrm{P}_{2} \mathrm{O}_{5}$ & $3.763868 \times 10^{-7}$ & $3.17927 \times 10^{-4}$ & 0.378 & 56.20468 \\
$-20 \mathrm{~B}_{2} \mathrm{O}_{3}$ & & & & \\
\hline
\end{tabular}

Whenever it is transferred to another site, the surrounding molecules respond to this perturbation with structural changes and the electron or hole is temporarily trapped in the potential well leading to atomic polarization. The electron resides at this site until it is thermally activated to migrate to another site.

\section{Conclusions}

The binary glassy systems $60 \mathrm{~V}_{2} \mathrm{O}_{5}-(40-\mathrm{x}) \mathrm{P}_{2} \mathrm{O}_{5}-\mathrm{xB}_{2} \mathrm{O}_{3}$ were prepared by melt quenching technique. The value of conductivity at room temperature was found to be higher for 20 mol $\% \mathrm{~B}_{2} \mathrm{O}_{3}$. The activation energy value was observed to be lower as compare to others. This represents the theoretical agreement. The XRD study reveals that glassy systems shows the amorphous nature. The chemical composition in the system was confirmed through FTIR analysis.

\section{Acknowledgments}

Authors are thankful to Head, Department of Physics Sant Gadge Baba Amravati University, Amravati and Principal HVP Mandal's college of Engg. \& Tech., Amravati for providing necessary facilities.

\section{References}

1. St. Adams and J. Swenson, "Relaxation dynamics in AgI-doped silver vanadate superionic glasses", Phys. Rev. Lett. 84, 4144 (2000).

2. St. Adams and J. Swenson, Phys. Rev., B 63 , 54201 (2000).

3. S. Bhattacharya and A. Ghosh," Conductivity relaxation in some fast ion-conducting AgI$\mathrm{Ag}_{2} \mathrm{O}-\mathrm{V}_{2} \mathrm{O}_{5}$ glasses", Solid State Ionics 161, 61- 65 (2003).

4. R.J. Barczyński, P. Król and L. Murawski, "Ac and dc conductivities in $\mathrm{V}_{2} \mathrm{O}_{5}-\mathrm{P}_{2} \mathrm{O}_{5}$ glasses containing alkaline ions", Journal of Non-Crystalline Solids 356, 1965-1967 (2010).

5. R.V. Barde and S.A. Waghuley, "dc Electrical conductivity of $\mathrm{V}_{2} \mathrm{O}_{5}-\mathrm{P}_{2} \mathrm{O}_{5}$ binary glassy systems", J. Phys.:Conference Series, 365, 012019 (2012).

6. R.V. Barde and S.A. Waghuley," $\mathrm{V}_{2} \mathrm{O}_{5}-\mathrm{P}_{2} \mathrm{O}_{5}$ Glass Ceramic as a Resistive Solid-State CO2 Gas Sensor", Asian Journal of Chemistry; Vol. 24, No. 12, 5622-5624 (2012).

7. A. Terczynska-Madej, K. Cholewa-Kowalska and M. Laczka, "The effect of silicate network modifiers on colour and electron spectra of transition metal ions", Opt. Mater. 32, (11) 1456 (2010). 
8. P. V. Reddy, C. Laxmikanth, V. Prasanth Kumar, N. Veeraiah and P. Kistaiah, "Optical and thermoluminescence properties of $\mathrm{R}_{2} \mathrm{O}-\mathrm{RF}-\mathrm{B}_{2} \mathrm{O}_{3}$ glass systems doped with MnO”, J. NonCryst. Solids 351, 3752 (2005).

9. A. Ramesh Babu, Ch. RajyaSree, P.M. Vinaya Teja, S. Yusub and D. Krishna Rao, "Influence of manganese ions on spectroscopic and dielectric properties of $\mathrm{LiF}-\mathrm{SrO}-\mathrm{B}_{2} \mathrm{O}_{3}$ glasses", Journal of Non-Crystalline Solids 358, 1391-1398 (2012).

10. G.D. Khattak and A. Mekki, "Structure and electrical properties of SrO-borovanadate

11. $\left(\mathrm{V}_{2} \mathrm{O}_{5}\right) 0.5(\mathrm{SrO}) 0.5 \mathrm{y}\left(\mathrm{B}_{2} \mathrm{O}_{3}\right)$ y glassses", J. of Phys. and Chem. of Solids 70, 1330-1336 (2009).

12. Y. D. Yiannopoulos, G. D. Chryssikos and E. I. Kamitsos, "Structure and properties of alkaline earth borate glasses", Physics and Chemistry of Glasses, 42 (3), 164-172(2001).

13. E. E. Horopanitis and G. Perentzis, A. Beck, L. Guczi, G. Peto, and L. Papadimitriou, "Structural and Physical Properties of $\mathrm{Fe}_{2} \mathrm{O}_{3}-\mathrm{B}_{2} \mathrm{O}_{3}-\mathrm{V}_{2} \mathrm{O}_{5}$ Glasses", J. of Non-Crystalline Solids, 354, 374-379 (2008). 